\title{
International Policy Coordination and Simple Monetary Policy Rules
}

WOLFraM Berger ${ }^{\mathrm{a}}$

JEL classification: F41, F42, E52, E58

Keywords: policy coordination, policy rule, consumer price targeting, producer price targeting, monetary targeting

\section{Introduction}

What is the optimal design of monetary policy in open economies? This is a long-standing issue in monetary economics. From the most recent debate it is far from clear that monetary policy in open economies should have any international dimension at all. Several writers including Clarida, Gali and Gertler (2002), Gali and Monacelli (2005) and Obstfeld and Rogoff (2002) make a strong case in favor of an inward-looking monetary policy. They argue that producer prices should be chosen as a target for welfare maximizing monetary policy. The baseline of these studies is that international integration in goods and financial markets decreases the need to take account of macroeconomic developments abroad when deciding about the optimal monetary policy stance. According to these authors there is in effect no difference in the policy problem faced by policymakers in closed and open economies. However, authors such as Corsetti and Pesenti (2005), Devereux, Lane and Xu (2004), Kollmann (2002), Smets and Wouters (2002) and Sutherland $(2005,2006)$, point out that this result only holds in relatively simple models. More complex models imply that targeting producer prices is generally not optimal.

Hence, the debate in the literature on optimal monetary policy in times of highly integrated goods and financial markets is far from settled. The optimal choice of the monetary policy target, the weight assigned to external factors in monetary policy decisions and the question, which simple, i.e. non-optimal,

a IESEG School of Management and LEM (Lille - Economics and Management - UMR CNRS, 8179), 3 rue de la digue, 59000 Lille, France. Phone +33 3205458 92, fax +33 3205748 55, email w.berger(at)ieseg.fr, and Technical University of Cottbus, Konrad-Wachsmann-Allee 1, 03046 Cottbus, Germany. 
targeting rule can best support the efficient resource allocation belong to the issues that are controversially discussed.

Employing a stochastic general equilibrium framework of the New Keynesian type, this paper addresses these questions by accounting for an important change in the nature of international cross-country linkages brought about by globalization. The production sequence of final consumption goods increasingly stretches across many countries and is associated with vertical trade. In the light of these changes, the interdependence of countries is increasingly based on trade along vertical production chains. That is, cross-border trade involves both intermediate and final goods (see Hummels, IsHi and YI, 2001 and YI, 2003). The aim of this paper is to investigate how these structural changes impact the monetary policy design.

We therefore differentiate between final consumption goods and the intermediate goods needed to produce them. A fraction of final goods producers has to set the nominal prices of consumer goods in advance of the realization of shocks, while prices of intermediate goods are taken to be perfectly flexible. We further suppose that the degree of pass-through for consumption goods prices may be less than complete, and as in Sutherland (2005), both productivity and cost-push shocks are considered. We are not only interested in the optimal monetary policy in this model but also investigate a range of simple targeting rules as guidelines to assess policy options and prepare policy decisions.

Obstfeld (2001) and Devereux and Engel (2007) also consider two-stage production processes but, contrary to our model, trade only occurs on one level in their models. HuANG and LiU (2004) investigate the impactof monetary shocks in a model with a multistage production chain. SHI and XU (2007) also present a model with more than one production stage and stage-specific productivity shocks and examine the optimal monetary policy in this framework. They also deal with the value of exchange rate flexibility under full and zero pass-through. Our approach differs from these previous studies. We are not only interested in the welfare-maximizing monetary policy but also in the welfare effects of simple policy rules in the presence of different types of shocks - productivity and costpush - and varying degrees of pass-through and cross-country interdependence in production. The goal is to present an encompassing model that enables us to examine whether and how a range of different factors influences the effects and, therefore, the design of monetary policy in open economies.

In this model, and in contrast to other related papers such as those cited above, world aggregate welfare is maximized when monetary policy responds to both types of shocks irrespective of whether they originate at home or abroad. Further, which simple targeting rule performs best in welfare terms in our model hinges 
critically on two factors, the degree of the cross-country vertical integration in production and the relative importance of productivity and cost-push shocks. Generally, following a policy rule that allows for some degree of price flexibility such as monetary targeting generates better welfare results than strictly targeting a well-defined price index in the presence of comparatively strong cost-push shocks. However, if productivity shocks predominate, a well-defined price index like the producer or the consumer price should be chosen as the monetary policy objective. If price targeting rules turn out to be best, the degree of vertical integration is decisive for which price index fares best as monetary policy objective.

Producer price index targeting only generates better welfare results than CPI targeting if vertical integration between countries is either rather low or rather high. Stabilizing foreign goods prices, too, as is done under CPI targeting does not yield any additional benefit then. In these cases, the consumption goods production nearly entirely relies on either domestic or foreign inputs so that the marginal production costs of home and foreign consumption goods (and thus their prices) are almost completely determined in either country. A policy that is only concerned with the stabilization of domestically produced goods prices - where, from a global point of view, it does not matter whether home goods prices are stabilized by home or foreign monetary adjustments - therefore comes closest to the optimal policy rule for this parameter combination. Our analysis of simple targeting rules therefore lends support to the conclusion derived in other papers (see above) that the producer price index is the optimal choice of a monetary policy target in an open economy only under very special conditions.

These results extend previous work in the literature on monetary policy rules. In a related paper, SutHerLand (2005) also finds that the welfare performance of a range of simple targeting rules depends on the relative volatility of costpush and productivity shocks. However, as opposed to the model presented in this paper, Sutherland does not aim at examining the effect of increasing crosscountry interdependence on the choice of simple monetary rules. ${ }^{1}$ A large part of the literature investigates simple monetary policy rules by using Taylor type rules (see, e.g. Feve, Matheron and Poilly, 2007 who estimate Taylor rules for the eurozone and Bullard and Singh, 2008 as recent examples). ${ }^{2}$ Leith

1 Another major difference between Sutherland's and this paper is that in our model not only productivity but also cost-push shocks give rise to changes in the socially optimal resource allocation and thus call for a monetary policy reaction.

2 It would also have been possible to model the simple policy rules in the form of instrument (Taylor-type) rules in this paper. See, e.g., McCallum and Nelson (2005) and Svensson (2005) for a discussion on the merits of targeting and instrument rules. 
and WREN-LEWIS (2009) investigate whether consumer price inflation might be a better target than producer price inflation in a two-country model. They also argue in favor of the producer price index as the monetary policy objective based, however, on a different reasoning than the literature cited above. They conclude that the adoption of inflation targets based on consumer prices could be a cause of concern since that may result in indeterminacy, such that there will not be a unique perfect foresight equilibrium path. This can be avoided by choosing the producer price index. Other papers demonstrate the merits of an interest rate peg in a standard New Keynesian model of a closed economy (Hoermann and Schabert, 2009) or argue in favor of forecast-based rules (Batini, Harrison and Millard, 2003 in a model that is calibrated using data for the UK). The closed economy context and the inclusion of inflation forecast rules, i.e. rules that prescribe an reaction to deviations of expected inflation from target, distinguish the latter two papers significantly from ours.

The remainder is structured as follows. The model is developed in the next section. In section 3, the welfare criterion is derived and the determination of consumption and output is discussed. In section 4, the optimal monetary policy rule and welfare under the optimal policy rule are derived. Section 5 compares the welfare results of four simple targeting rules with the help of a simple numerical example. Section 6 concludes.

\section{The Model}

\subsection{Basic Assumptions}

The world economy consists of two equally sized countries inhabited by a continuum of households of the yeoman-farmer type. ${ }^{3}$ Households over the $[0,1]$ interval live in the home country, while households in the $(1,2]$ interval are residents of the foreign country. Analogously, goods over the $[0,1]$ interval are produced in the home country while goods in the $(1,2]$ interval are produced in the foreign country. In the following sections, the equations for the representative home household are presented while the equations for the representative foreign household are omitted most of the time. Generally, mirror images hold for the foreign country. Throughout the paper, an asterisk indicates a foreign variable.

3 To keep the model tractable and to be able to derive results analytically, we stick to a static model. 
Following, e.g., Sutherland (2005) we suppose that consumption goods are produced by two type of agents. The first type of agents, called "fixed-price agents", is required to set prices before shocks occur and monetary policy is set. The second type, called "flex-price agents", operates in markets where prices are set after the realization of shocks and the setting of monetary policy. In both countries, the share of fixed-price agents in the population is given by $v$, so that $1-v$ is the share of flex-price agents. $v$ can therefore be interpreted as a measure of the degree of price stickiness. ${ }^{4}$ Markets for intermediate goods, however, are characterized by full price flexibility. That is, all intermediate goods producers are flex-price producers. In the following, the subscript "1" ("2") will indicate variables related to fixed-price (flex-price) agents.

\subsection{Preferences and Prices}

The utility of the representative home household is given by

$$
U=E\left[\log C+\chi \log \frac{M}{P}-K y(z)\right], \chi>0 .
$$

$C$ denotes a consumption index defined below; $M$ denotes the domestic end-ofperiod money stock, $P$ is the consumer price index (also defined below) and $y(z)$ is the output of intermediate good $z . E$ is the rational expectation operator and $K$ denotes a stochastic shock to the labor supply (productivity shock). The third term on the right hand side expresses the disutility of work effort in terms of output. ${ }^{5}$ Both home and foreign shocks are symmetrically distributed over a finite interval with $E[\log K]=E\left[\log K^{*}\right]=0$ and $V A R[\log K]=V A R\left[\log K^{*}\right]=\sigma_{K}^{2}$.

The consumption indices are defined as:

$$
C=2\left(C_{H}\right)^{\frac{1}{2}}\left(C_{F}\right)^{\frac{1}{2}}, C^{*}=2\left(C_{F}^{*}\right)^{\frac{1}{2}}\left(C_{H}^{*}\right)^{\frac{1}{2}} .
$$

Combined with the assumption of zero initial non-monetary wealth, the structure of the preferences implies that financial markets are redundant (see Cole and Obstfeld (1991) and Corsetti and Pesenti (2005)). Home and foreign

4 This framework can be thought of as a static version of Calvo (1983)'s staggered price setting.

5 The production technology is linear in work effort (see below). 
consumers share their consumption risks perfectly without financial markets. The ratio of marginal utilities in consumption is equal to the ratio of aggregate prices, $\left(C / C^{*}\right)^{-1}=\mathrm{P} /\left(S P^{*}\right)$, where $P$ and $P^{*}$ denote the home and the foreign countries' $\mathrm{CPI}$ and $S$ is the exchange rate expressed as the price of foreign currency in home currency.

$C_{H}$ and $C_{F}$ are indices of home and foreign differentiated consumption goods with

$$
C_{H}=\mu\left(C_{H, 1}\right)^{\nu}\left(C_{H, 2}\right)^{1-\nu}, C_{F}=\mu\left(C_{F, 1}\right)^{\nu}\left(C_{F, 2}\right)^{1-\nu}
$$

with $\mu=v^{-v}(1-v)^{-(1-v)}$. The bundles of fixed-price and flex-price consumption goods are defined as CES aggregates over individual consumption goods with the elasticity of substitution $\phi$ for all bundles. $C_{H, i}(z)$ and $C_{F, i}\left(z^{*}\right)$ denote a home household's consumption of a particular brand produced by type $i$. $z$ denotes a home variety, $z \in[0,1]$, while $z^{*} \in(1,2]$ denotes a foreign variety.

The price indices corresponding to the consumption goods indices are derived in the usual way. The CPI and the producer price indices are given by

$$
\begin{gathered}
P=P_{H}^{\frac{1}{2}} P_{F}^{\frac{1}{2}} \\
P_{H}=P_{H, 1}^{v} P_{H, 2}^{1-v}, P_{F}=P_{F, 1}^{v} P_{F, 2}^{1-v} .
\end{gathered}
$$

The price indices of fixed-price and flex-price goods are

$$
\begin{aligned}
& P_{H, 1}=\left[\frac{1}{v} \int_{0}^{v} P_{H, 1}(z)^{1-\phi} d z\right]^{\frac{1}{1-\phi}}, \quad P_{H, 2}=\left[\frac{1}{1-v} \int_{V}^{1} P_{H, 2}(z)^{1-\phi} d z\right]^{\frac{1}{1-\phi}}, \\
& P_{F, 1}=\left[\frac{1}{v} \int_{1}^{1+v} P_{F, 1}\left(z^{*}\right)^{1-\phi} d z^{*}\right]^{\frac{1}{1-\phi}}, \quad P_{F, 2}=\left[\frac{1}{1-v} \int_{1+v}^{2} P_{F, 2}\left(z^{*}\right)^{1-\phi} d z^{*}\right]^{\frac{1}{1-\phi}} .
\end{aligned}
$$

$P_{H, i}(z)$ and $P_{F, i}\left(z^{*}\right)$ are individual goods prices denominated in home currency.

\subsection{Production}

We differentiate between final consumption goods and the intermediate goods needed to produce them. In both countries, producers in the final consumption goods sector and in the intermediate goods sector enjoy a degree of monopoly 
power. Final commodities are produced by bundling a continuum of differentiated intermediate goods. Both countries operate the same technology:

$$
Y_{H, i}(z)=\kappa y_{H}^{\alpha} y_{F}^{1-\alpha}, i=1,2 \text {, }
$$

with $\kappa=\alpha^{-\alpha}(1-\alpha)^{-(1-\alpha)} \cdot y_{H}$ and $y_{F}$ denote bundles of home and foreign intermediate goods, which are defined as CES aggregates over individual intermediate goods with an elasticity of substitution of $\omega$. The parameter $\alpha$ is understood as a measure of the degree of vertical integration in goods production. A high value of $\alpha$ means that cross-country vertical integration in production is quite low while a low value of $\alpha$ indicates a quite pronounced cross-country interdependence in production.

The demand for home intermediates stems from home and foreign countries' consumption goods producers. The aggregate equilibrium conditions for home and foreign intermediate goods read

$$
\begin{gathered}
y=y_{H}+y_{H}^{*}=\left[\frac{p_{H}}{p_{I}}\right]^{-1} \alpha Y_{H}+\left[\frac{p_{H}}{p_{I}^{*} S}\right]^{-1}(1-\alpha) Y_{F}^{*}, \\
y^{*}=y_{F}^{*}+y_{F}=\left[\frac{p_{F}^{*}}{p_{I}^{*}}\right]^{-1}(1-\alpha) Y_{H}+\left[\frac{p_{F}^{*} S}{p_{I}}\right]^{-1} \alpha Y_{F}^{*} .
\end{gathered}
$$

$p_{H}$ and $p_{F}^{*}$ are the price indices of the home and foreign intermediate goods bundles. $p_{I}$ and $p_{I}^{*}$ denote the intermediate goods price indices in home and foreign currency which are given by $p_{I}=\left(p_{H}\right)^{\alpha}\left(S p_{F}^{*}\right)^{(1-\alpha)}$ and $p_{I}^{*}=\left(p_{F}^{*}\right)^{\alpha}\left(p_{H} / S\right)^{(1-\alpha)}$. The law of one price holds for individual intermediate goods. Purchasing power parity in terms of intermediate goods bundles, however, does not hold owing to the home bias in the production of final goods.

It is further assumed that each household produces a differentiated intermediate good. The production of an intermediate good requires labor input only. The domestic and foreign production technologies are identical and are linear in hours of work. One unit of labor input yields one differentiated intermediate good. ${ }^{6}$

6 The production technology can be explicitly written as $y(z)=K^{-1} h$ with $h$ denoting the work effort of the representative household. Shocks $K>0$ are therefore negative productivity shocks reducing the quantity of goods produced with a given labor input. 


\subsection{Consumption and Money Demand}

Households decide optimally about their (intratemporal) consumption allocation and their money holdings. Home household's demands for home fixed-price and flex-price goods, $C_{H, 1}(z)$ and $C_{H, 2}(z)$, and for foreign fixed-price and flex-price goods, $C_{F, 1}\left(z^{*}\right)$ and $C_{F, 2}\left(z^{*}\right)$, are given by

$$
\begin{aligned}
& C_{H, 1}(z)=\frac{1}{v}\left[\frac{P_{H, 1}(z)}{P_{H, 1}}\right]^{-\phi} C_{H, 1}, \quad C_{H, 1}=v \frac{1}{2}\left[\frac{P_{H, 1}}{P_{H}}\right]^{-1}\left[\frac{P_{H}}{P}\right]^{-1} C, \\
& C_{H, 2}(z)=\frac{1}{1-v}\left[\frac{P_{H, 2}(z)}{P_{H, 2}}\right]^{-\phi} C_{H, 2}, \quad C_{H, 2}=(1-v) \frac{1}{2}\left[\frac{P_{H, 2}}{P_{H}}\right]^{-1}\left[\frac{P_{H}}{P}\right]^{-1} C \text {, } \\
& C_{F, 1}\left(z^{*}\right)=\frac{1}{v}\left[\frac{P_{F, 1}\left(z^{*}\right)}{P_{F, 1}}\right]^{-\phi} C_{F, 1}, \quad C_{F, 1}=v \frac{1}{2}\left[\frac{P_{F, 1}}{P_{F}}\right]^{-1}\left[\frac{P_{F}}{P}\right]^{-1} C, \\
& C_{F, 2}\left(z^{*}\right)=\frac{1}{1-v}\left[\frac{P_{F, 2}\left(z^{*}\right)}{P_{F, 2}}\right]^{-\phi} C_{F, 2}, \quad C_{F, 2}=(1-v) \frac{1}{2}\left[\frac{P_{F, 2}}{P_{F}}\right]^{-1}\left[\frac{P_{F}}{P}\right]^{-1} C \text {. }
\end{aligned}
$$

Foreign demands can be described by similar equations.

The representative home household of type $i=1,2$ faces a budget constraint that is given by:

$$
\begin{aligned}
M-M_{0}= & \left(1+\tau^{f}\right)\left[P_{H, i}(z) C_{H, i}(z)+S P_{H, i}^{*}(z) C_{H, i}^{*}(z)\right] \\
& +\left(1+\tau^{i n t}\right) p_{H}(z) y(z)-P C-P T-p_{H} y_{H}-p_{F} y_{F} .
\end{aligned}
$$

$M_{0}$ and $M$ are money holdings at the beginning and at the end of the period. $T$ denotes real lump-sum taxes in terms of the consumption index and $\tau^{\text {int }}$ and $\tau^{f}$ are (the usual) production subsidies for final $(f)$ and intermediate goods (int) producers. Households' optimal money demand is derived by maximizing their utility function subject to their budget constraint. The first order condition for the optimal money demand implies that money market equilibrium is given if $\mathrm{M}=\chi P C$. The money supply is set by the central bank by following a monetary rule that may depend on all shocks. 


\subsection{Optimal Price Setting}

\subsubsection{Consumption Goods Sector}

The consumption goods sectors in both countries are subject to cost-push shocks. Cost-push shocks are introduced into the model as random fluctuations in the (net) mark-up over marginal costs that monopolistically competitive final goods producers set (see Sutherland, 2005). In the consumption goods sector, the mark-up augmented by the production subsidy can be derived as $\varphi \equiv \phi /\left[(\phi-1)\left(1+\tau^{f}\right)\right]$. Hence, fluctuations in $\varphi$ can either be caused by random changes in the degree of monopoly power (reflected in $\phi$ ) or by random changes in the production subsidy $\left(\tau^{f}\right) . \varphi$ is assumed to be symmetrically distributed over a finite interval with $E[\log \varphi]=E\left[\log \varphi^{*}\right]=0$ and $\operatorname{VAR}[\log \varphi]=\operatorname{VAR}\left[\log \varphi^{*}\right]=\sigma_{\varphi}{ }^{2}$.

As discussed in the Introduction, it is assumed that the pass-through of exchange rate changes into prices may be incomplete. Following Corsetti and Pesenti (2005), incomplete pass-through can formally be represented by

$$
P_{H, i}^{*}(z)=\breve{P}_{H, i}(z) S^{-\eta^{*}} \text { and } P_{F, i}\left(z^{*}\right)=\breve{P}_{F, i}^{*}\left(z^{*}\right) S^{\eta}
$$

where $0 \leq \eta=\eta^{*} \leq 1 . \breve{P}_{H, i}(z)$ and $\breve{P}_{F, i}^{*}$ denote the predetermined components of export prices that are set by final goods producers and that are denominated in the producers' currency.

Fixed-price agents are required to set prices one period ahead of time, i.e. before shocks have been realized and monetary policy has been set. Since, in equilibrium, all fixed-price producers choose the same price, optimal prices can be expressed in terms of prices of consumption bundles. The optimal preset prices for home and foreign fixed-price consumption goods sold at home and abroad can be derived as ${ }^{7}$

$$
P_{H, 1}=\alpha E \frac{\varphi p_{I} C_{H, 1}\left(\frac{K}{p_{H}}-\frac{\tau^{i n t}}{P C}\right)}{\frac{C_{H, 1}}{P C}}, P_{F, 1}^{*}=\alpha E \frac{\varphi^{*} p_{I}^{*} C_{F, 1}^{*}\left(\frac{K^{*}}{p_{F}^{*}}-\frac{\tau^{i n t}}{P^{*} C^{*}}\right)}{\frac{C_{F, 1}^{*}}{P^{*} C^{*}}},
$$

7 In a non-static version of the model, staggered price setting (CALvo, 1983) could be introduced as well as other refinements such as persistent shocks. We leave that for future research. 


$$
\breve{P}_{H, 1}=\alpha E \frac{\varphi p_{I} C_{H, 1}^{*}\left(\frac{K}{p_{H}}-\frac{\tau^{i n t}}{P C}\right)}{\frac{C_{H, 1}^{*} S^{1-\eta}}{P C}}, \quad \breve{P}_{F, 1}^{*}=\alpha E \frac{\varphi^{*} p_{I}^{*} C_{F, 1}\left(\frac{K^{*}}{p_{F}^{*}}-\frac{\tau^{i n t}}{P^{*} C^{*}}\right)}{\frac{C_{F, 1}}{P^{*} C^{*} S^{1-\eta}}} .
$$

Fixed-price agents incorporate a risk premium in prices which depends on the second moments of variables. Flex-price agents, however, need not incorporate a risk premium because they do not face any uncertainty. The first order condition for flex-price agents holds ex-post. Optimal prices set by flex-price producers are given by

$$
\begin{aligned}
& P_{H, 2}=\varphi p_{I}\left(\frac{K M}{p_{H}}-\tau^{i n t}\right), \quad P_{F, 2}^{*}=\varphi p_{I}^{*}\left(\frac{K^{*} M^{*}}{p_{F}^{*}}-\tau^{i n t}\right), \\
& \breve{P}_{H, 2}=\varphi p_{I}\left(\frac{K M}{p_{H}}-\tau^{i n t}\right) \frac{1}{S^{1-\eta}}, \quad \breve{P}_{F, 2}^{*}=\varphi p_{I}^{*}\left(\frac{K^{*} M^{*}}{p_{F}^{*}}-\tau^{i n t}\right)(1-\eta) S .
\end{aligned}
$$

\subsubsection{Intermediate Goods Sector}

For simplification it is assumed that there is perfect price flexibility and complete pass-through on the intermediate goods markets. ${ }^{8}$ Optimal price setting by intermediate goods producers yields

$$
p_{H}=\psi K M \text { and } p_{F}^{*}=\psi K^{*} M^{*},
$$

where $\psi$ denotes the net mark up given by $\psi=\omega /\left((\omega-1)\left(1+\tau^{i n}\right)\right)$. For the remainder of the paper it is assumed that $\tau^{i n t}=1 /(\omega-1)$ so that $\psi=1$. The monopolistic distortion in the intermediate goods sector is completely offset by the production subsidy.

8 Devereux and Engel (2007) argue that prices of intermediate goods are more flexible than prices of consumption goods. Moreover, empirical studies show that the degree of pass-though is by far higher for imported goods than for consumption goods (see CAMPA, GoldBerg and Gonzalez-Minguez, 2005). 


\section{Welfare, Output and Consumption}

\subsection{Methodology and Welfare Criterion}

To solve the model we use second order approximations around the non-stochastic steady state. The non-stochastic steady state of the model, denoted by a bar over a variable, is characterized by $\bar{K}=\bar{K}^{*}=1, \bar{\varphi}=\bar{\varphi}^{*}=1$ and $\bar{\sigma}_{K}^{2}=\bar{\sigma}_{\varphi}^{2}=0$. All households then produce and consume the same quantity of goods.

Households' utility function provides a measure of welfare that is used to study the welfare results of monetary policy rules. As usual in the literature, the utility service of real balances is assumed small enough to be neglected.' The paper focuses on the coordinated choice of policy rules where policymakers are assumed to aim at maximizing the welfare of the world population as a whole. Policy measures are therefore evaluated at the global level. ${ }^{10}$ The aggregate welfare criterion can then be formulated as

$$
W^{G}=\tilde{W}+\tilde{W}^{*}=E\left[\log C+\log C^{*}-K y-K^{*} y^{*}\right] .
$$

A second-order approximation of the welfare criterion is given by

$$
\tilde{W}^{G}=E\left[\hat{C}+\hat{C}^{*}-\hat{y}-\hat{y}^{*}-\frac{1}{2}(\hat{y}+\hat{K})^{2}-\frac{1}{2}\left(\hat{y}^{*}+\hat{K}^{*}\right)^{2}\right]+o^{3} .
$$

$\tilde{W}^{G}$ denotes the expected deviation of global welfare from its non-stochastic steady state value. Terms of order $n$ and above are collected in $o^{n}$. A hat over a variable indicates a $\log$ deviation of that variable from its deterministic steady state, formally defined as $\hat{X}=\log (X / \bar{X})$. Equation (15) can be written more concisely by noting that equations (8) and the consumption subindices imply that $\hat{C}+\hat{C}^{*}-\hat{y}-\hat{y}^{*}=0$.

$$
\tilde{W}^{G}=-E\left[\frac{1}{2}(\hat{y}+\hat{K})^{2}+\frac{1}{2}\left(\hat{y}^{*}+\hat{K}^{*}\right)^{2}\right]+o^{3} .
$$

9 Formally, $\chi$ is assumed to be infinitesimally small, $\chi \rightarrow 0$. See, e.g., Овstfeld and Rogoff (1995).

10 This approach, which is also chosen by SuTHERLAND (2005), is adopted because of its analytic simplicity. However, since both countries have an identical structure, both would adopt the same policy rule in a Nash equilibrium. The policy approach - coordinated or uncoordinated - will therefore only affect the absolute welfare level but not the welfare ranking of the policy rules and is thus innocuous for the paper's conclusions. 
Welfare in the coordinated regime depends only on the fluctuations of the expected log deviations of the disutilities of work effort around their steady state values. ${ }^{11}$

The model is further simplified by assuming that all shocks are uncorrelated with one another.

\subsection{Determination of Output and Consumption}

Before we delve into the welfare analysis of monetary policy the intuition of the model can be illustrated by looking at the ex-post values of output and consumption. To do that we only need to consider first-order accurate solutions. ${ }^{12}$ Note first that all pre-set prices only contain terms of order two and above in $\log$-deviation form. A first-order accurate solution for pre-set prices can therefore be written as

$$
\hat{P}_{H, 1}=\hat{\breve{P}}_{H, 1}=0+o^{2} \cdot{ }^{13}
$$

Equivalent equations hold for foreign pre-set prices.

Using the definition of overall consumption given in equation (2), realized consumption can be expressed as

$$
\begin{aligned}
\hat{C} & =v \hat{M}-\frac{1}{2}(1-v)\left[\hat{\varphi}+\varphi^{*} \hat{K}+\hat{K}^{*}\right]-\frac{1}{2} v \eta \hat{S}+o^{2} \\
\hat{C}^{*} & =v \hat{M}^{*}-\frac{1}{2}(1-v)\left[\hat{\varphi}+\varphi^{*} \hat{K}+\hat{K}^{*}\right]+\frac{1}{2} v \eta \hat{S}+o^{2},
\end{aligned}
$$

11 Although work effort enters households' utility function linearly (see equation (1)), households' utility decreases in the volatility of work effort in the approximated utility function (16). This effect is based on Jensen's inequality as pointed out by SutHerLand (2004).

12 Note that, to solve the model, a second order accurate solution for the variance of $\hat{y}$ and $\hat{y}^{*}$ must be obtained. These can be derived from a first order approximation of the levels $\hat{y}$ and $\hat{y}^{*}$.

13 Since the only stochastic variables in the model are the home and foreign shocks and thus the monetary stances that depend on the shocks (see equation (22) below), the log deviation of the pre-set prices around their steady states depend on the first and second moments of these variables. Since the first moments - the expected value - is equal to zero, only second moments (variances and co-variances) remain. 
where we considered that from equation (12) and its foreign counterpart it follows that

$$
\begin{gathered}
\hat{P}_{H, 2}=\alpha \hat{K}+(1-\alpha) \hat{\varphi}+\varphi^{*} \hat{K}+\hat{K}^{*}+\hat{\varphi}+\hat{M} \text { and } \\
\hat{P}_{F, 2}^{*}=\alpha \hat{K}^{*}+(1-\alpha) \hat{K}+\hat{\varphi}^{*}+\hat{M}^{*} .
\end{gathered}
$$

As long as a subset of producers is able to adjust prices, consumption in the home and in the foreign country are affected by home and foreign productivity and by home and foreign cost-push shocks. The reason is that final goods production in both countries relies on home and foreign inputs and intermediate goods prices vary with $\hat{K}$ and $\hat{K}^{*}$, respectively (see equation (13)). Home and foreign cost-push shocks enter equation (17) through the prices of flex-price consumption goods. Intuitively, monetary policy adjustments directly affect consumption unless all producers are flex-price producers, i.e. unless $v=0$. Exchange rate changes give rise to variations in the consumption level as long as they affect the prices of fix-price consumption goods, i.e. for $\eta, v>0$.

Output of consumption goods is given by

$$
\begin{aligned}
\hat{Y}_{H}= & \frac{1}{2} v(1+\eta) \hat{M}+\frac{1}{2} v(1-\eta) \hat{M}^{*} \\
& -(1-v)\left[\hat{\varphi}+\alpha \hat{K}+(1-\alpha) \hat{K}^{*}\right]+o^{2}, \\
\hat{Y}_{F}^{*}= & \frac{1}{2} v(1+\eta) \hat{M}^{*}+\frac{1}{2} v(1-\eta) \hat{M} \\
& -(1-v)\left[\hat{\varphi}^{*}+\alpha \hat{K}^{*}+(1-\alpha) \hat{K}\right]+o^{2} .
\end{aligned}
$$

Intuitively, an increase in the home money supply raises consumption spending so that home output also increases as long as $v>0$. For $v=0$, however, monetary changes are completely absorbed by price changes and do not affect real aggregates. Monetary policy adjustments abroad affect home consumption goods output through spill-over effects (for $v>0$ ) unless they are completely absorbed by exchange rate changes, i.e. if $\eta=1$. Output is further impacted by productivity and cost-push shocks if they give rise to price changes on the input or final consumption goods level, i.e. for $v<1$.

Intermediate goods output in both countries can be expressed as

$$
\begin{aligned}
\hat{y}= & b\left[\hat{K}^{*}-\hat{K}\right]+\frac{1}{2} v(1+u) \hat{M}+\frac{1}{2} v(1-u) \hat{M}^{*} \\
& -(1-v)\left[\alpha \hat{\varphi}+(1-\alpha) \hat{\varphi}^{*}+(1-b) \hat{K}+b \hat{K}^{*}\right]+o^{2},
\end{aligned}
$$




$$
\begin{aligned}
\hat{y}^{*}= & b\left[\hat{K}-\hat{K}^{*}\right]+\frac{1}{2} v(1+u) \hat{M}^{*}+\frac{1}{2} v(1-u) \hat{M} \\
& -(1-v)\left[\alpha \hat{\varphi}^{*}+(1-\alpha) \hat{\varphi}+(1-b) \hat{K}^{*}+b \hat{K}\right]+o^{2},
\end{aligned}
$$

with $b=2 \alpha(1-\alpha)$ and $u=\eta(2 \alpha-1)$. As long as there is a minimum degree of price stickiness that allows monetary policy to affect real activity, a monetary adjustment anywhere in the world affects both countries. For example, an increase in the home money supply stimulates home consumption demand (see above) that in turn causes an expansion of home and foreign intermediate goods output. Equations (19) also show that output production is shifted to the country with the most favorable productivity shock (first term on the right hand side) as long as home and foreign input goods are substitutes, i.e. $0<\alpha<1$. Moreover, output and thus work effort are affected by cost-push shocks at home and abroad. Cost-push shocks affect the output of intermediate goods as long as there is a degree of price flexibility in the economies, i.e. $v<1$. Flex-price producers react to a positive cost-push shock by raising consumption goods prices. The resulting contraction in demand for consumption goods translates into a fall in demand for intermediate goods at home and abroad. For the same reason, productivity shocks at home and abroad affect $y$ and $y^{*}$ if $v<1$. The resulting price adjustments on the intermediate goods level are passed on to the consumption goods level. If, however, prices of consumption goods are completely sticky, producers cannot pass the fluctuation in costs on to consumers and intermediate goods output remains unaffected. Instead, shocks lead to changes in final goods producers' profit margins.

\section{Optimal Monetary Policy and Policy Coordination}

\subsection{Optimal Monetary Policy Rule}

Monetary policy is conducted by following policy rules. Generally, it is assumed that central banks are able to pre-commit irrevocably to money supply rules. Before simple targeting rules are considered in the next section the welfare implications of following optimal monetary policy rules are derived as a benchmark for the remainder of the paper. As pointed out above, we concentrate on the cooperative solution as the best solution policymakers can achieve. It is supposed that a single world central bank chooses rules for the home and foreign money supplies that maximize world welfare given by $\tilde{W}+\tilde{W}^{*}$. The optimal monetary policy 
is set by following a monetary rule that may depend on the shocks $K, K^{*}, \varphi$ and $\varphi^{*}$. The home policy rule is given by $M=M_{0} K^{\delta_{K}} K^{*^{\delta} K^{*}} \varphi^{\delta_{\varphi}} \varphi^{*} \varphi^{*}$. Expressed in log deviation form, we have

$$
\hat{M}=\delta_{K} \hat{K}+\delta_{K^{*}} \hat{K}^{*}+\delta_{\varphi} \hat{\varphi}+\delta_{\varphi^{*}} \hat{\varphi}^{*}
$$

The reaction parameters $\delta_{K}, \delta_{K^{*}}, \delta_{\varphi}$ and $\delta_{\varphi^{*}}$ are chosen before shocks occur and prices are set.

\subsection{Optimal Monetary Policy and Welfare}

Optimal rules are chosen by optimally setting the feedback parameters $\delta_{K}$, $\delta_{K^{*}}, \delta_{\varphi}$ and $\delta_{\varphi^{*}}$ for the home economy and their counterparts $\delta_{K}^{*}, \delta_{K^{*}}^{*}, \delta_{\varphi}^{*}$ and $\delta_{\varphi^{*}}^{*}$ for the foreign economy. If monetary policy is internationally coordinated, the single world central bank specifies the home and foreign policy rules by choosing the following set of feedback parameters:

$$
\begin{aligned}
\delta_{K}^{C} & =\delta_{K^{*}}^{*^{C}}=-\frac{2 u v(2 b-u-1)}{v\left[1+u^{2}\left(u^{2}-2\right)\right]} \\
\delta_{K^{*}}^{C} & =\delta_{K}^{*^{C}}=\frac{2 u v(2 b+u-1)}{v\left[1+u^{2}\left(u^{2}-2\right)\right]} \\
\delta_{\varphi}^{C} & =\delta_{\varphi^{*}}^{*^{C}}=-\frac{2 \eta(1+\eta)(1-v)(1-4 \alpha(1-\alpha))}{v\left[1+u^{2}\left(u^{2}-2\right)\right]} \\
\delta_{\varphi^{*}}^{C} & =\delta_{\varphi}^{*^{C}}=\frac{2 \eta(1-\eta)(1-v)(1-4 \alpha(1-\alpha))}{v\left[1+u^{2}\left(u^{2}-2\right)\right]} .
\end{aligned}
$$

The superscript " $C$ " indicates the cooperative case. The feedback parameters for the coordinated solution show that the optimal monetary policy for complete price flexibility $(v=0)$ is undefined. In this case output and work effort are exogenously determined and completely independent of monetary policy (see equation (21)). Hence, aggregate welfare (16) cannot be affected by monetary policy. If, however, price flexibility is less than perfect, monetary policy is able to influence the resource allocation (see the discussion above).

Equations (21) show that both policymakers (generally) react to both home and foreign productivity and home and foreign cost-push shocks. A shock that lowers productivity in the intermediate goods sector $(\hat{K}>0)$ leads to an increase in the marginal production costs of consumption goods and causes the socially 
optimal level of work effort in the home country to fall. ${ }^{14}$ Flex-price consumption goods producers react by raising prices while fixed-price producers are unable to do so by definition. A monetary contraction is therefore required to stabilize marginal costs and thus the mark-up. However, whether this monetary contraction occurs in the home or in the foreign country depends on the degree of vertical integration given by $\alpha$. The policymaker, whose country uses relatively more of the home input goods to produce final consumption goods, is best suited to reduce work effort in the home country by reducing the demand for its consumption goods. The other country reacts exactly inversely and thus adds to the effect on the global resource allocation by intensifying the resulting exchange rate changes. Hence, monetary policy adjustments in both countries work in the same direction.

Neither the home nor the foreign policymaker react in the special case that $\alpha=1 / 2$. In this case, a productivity shock anywhere in the world cannot be smoothed by redirecting global consumption demand and thus work effort. Since both countries rely on home and foreign inputs in equal shares, shifting consumption from home to foreign goods or vice versa has no affect on work effort.

Sutherland (2005) points out that cost-push shocks do not give rise to any change in the socially optimal level of work effort. A welfare-maximizing monetary policy thus does not provide for a response to this type of shocks. In our model, however, cost-push shocks in one country also lead (generally) to a monetary policy reaction in both countries. As long as there is a minimum degree of price flexibility, responding to cost-push shocks is optimal for the policymakers unless $\alpha=1 / 2$.

The existence of a home bias $(\alpha \neq 1 / 2)$ gives the home and, if there is a certain but less than complete degree of pass-through $(0<\eta<1)$, the foreign policymakers an incentive to react. Flex-price producers in the consumption goods sector react to a positive cost-push shock $(\varphi>0)$ by raising prices. The resulting contraction in demand for flex-price consumption goods translates into a fall in demand for intermediate goods at home and abroad and thus affects work effort in both countries. To reduce work effort of fix-price producers a monetary contraction is required that gives rise to a fall in consumption demand. The foreign policymaker reacts exactly inversely. A shock $\varphi>0$ causes a foreign monetary expansion that reinforces the appreciation of the domestic currency and thus helps to redirect international demand away from home toward foreign consumption

14 As discussed above, global welfare depends only on the variance of the disutility of work effort (see equation (16)). 
goods. For similar reasons as spelled out above, the home and the foreign policymaker do not respond to cost-push shocks if $\alpha=1 / 2$.

Whether the foreign policymaker adjusts the foreign money supply in response to a home cost-push shock depends critically on the degree of pass-through $\eta$. While the strength of the home monetary policy response increases in $\eta$, the foreign policymaker reacts less aggressively if $\eta$ increases. The higher $\eta$ is, the more the adjustment burden is shifted to the home policymaker. If the pass-through is complete, the foreign money supply is not adjusted anymore if cost-push shocks occur in the neighbor country. Then, the substitution and the income effect of monetary changes abroad exactly cancel each other out. Similarly, if there is no pass-through $(\eta=0)$, the foreign policymaker does not react to home cost-push shocks because international demand cannot be shifted away from home towards foreign goods and vice versa through exchange rate changes.

If consumption goods prices are completely sticky $(v=1)$, there is no response to cost-push shocks when policies are coordinated, either. The reason is that in this case output of consumption goods is not affected by cost-push shocks and therefore work effort expended in the production of intermediates is not altered. ${ }^{15}$ Similarly, for $\alpha=1 / 2$ there is no reason for a monetary policy adjustment. If there is no home bias in the production of intermediate goods, the effects of a change in final goods demand are equally split between the home and the foreign country. Hence, the policymakers need not intervene to reach the welfare-maximizing allocation of work effort between both countries. Generally and in contrast to the work of SUTHERLAND (2005), however, not reacting to cost-push shocks is not optimal.

\section{Simple Rules and Welfare}

\subsection{Simple Targeting Rules}

The optimal monetary policy rules have a relatively simple form in this model. Optimal rules, however, might become highly complicated and hardly feasible to compute in more complex models and thus impossible to implement in practice. This section is therefore devoted to the analysis of simple, i.e. non-optimal, policy rules. Simple rules are not understood as a specification that the policymaker

15 As pointed out above, fixed-price output is insulated against cost-push shocks (cost-push shocks do not affect the socially optimal level of work effort) so that a monetary response for $v=1$ is not required. 
should follow mechanically. Instead, we interpret them as a guideline to assess policy options and prepare policy decisions. This implies that large departures from what these rules suggest need to be explained carefully. ${ }^{16}$ Hence, simple rules are considered as a means to think about the best monetary policy stance.

This section is therefore devoted to the welfare analysis of simple targeting rules. The key question now is: which simple policy rule best supports the world coordinated policy? Welfare associated with the targeting rules is evaluated at the global level, i.e. based on the global welfare criterion (16). Our aim is to evaluate the performance of price targeting rules such as producer and consumer price targeting that do not allow for fluctuations in a well-defined price index and of rules that allow for some degree of price flexibility and thus provide the policymaker with the opportunity to stabilize real aggregates as well. ${ }^{17}$ As an example for the latter type of policy rules we investigate monetary targeting (which implies the stabilization of nominal consumption through the money market equilibrium condition). We concentrate on symmetric policy regimes, i.e. we assume that the policymakers in both countries follow the same rule. ${ }^{18}$ We stick to a very basic formulation of policy rules to illustrate our points as discussed in the Introduction. For a discussion and evaluation of more complex non-optimal policy rules like forecast-based rules, the reader is referred to the literature reviewed above.

In our model, a targeting rule is taken to mean a rule that eliminates all fluctuations in the targeted variable. Hence, a rule that targets variable $X$ is modeled as a rule for the money supply that leads to $\hat{X}=0$ ex post. This is in line with McCallum and Nelson (1999), who define a targeting rule as a commitment to set the policy instrument rate so that a pre-defined target for the target variables is realized. ${ }^{19}$ In this paper, the simple targeting rules are expressed as statecontingent rules for the money supplies at home and abroad.

The specification of the policy rules for the home economy is summarized in Table (1) (see the Appendix for details). Generally, mirror images hold for the foreign economy.

16 Interpreted in this sense, a simple rule gives the central bank a fallback option for difficult times.

17 All rules are only considered in their strict form, i.e. policymakers are assumed to ignore other objectives.

18 Sutherland (2005) shows that asymmetric regimes are welfare inferior to symmetric ones in a model where both economies are mirror images of each other as in our model.

19 This definition is similar to the definition of a specific targeting rule introduced by SvENSSON (2002). Svensson, however, reserves the term target for variables that enter the policymaker's objective (loss) function. 
Table 1: Simple Targeting Rules

\begin{tabular}{ll}
\hline Target & Monetary Rule \\
\hline Producer Price Index & $\hat{M}^{P P I}=-\alpha \hat{K}-(1-\alpha) \hat{K}^{*}-\hat{\varphi}$ \\
Consumer Price Index & $\hat{M}^{C P I}=-\frac{1}{2}\left[\hat{K}+\hat{K}^{*}+\hat{\varphi}+\hat{\varphi}^{*}\right]$ \\
Money Supply & $\hat{M}^{M S}=0$ \\
\hline
\end{tabular}

In contrast to producer price index and money supply targeting and in accordance with the optimal policy rule the policymaker generally responds to all types of shocks irrespective of their origin under a policy of consumer price index targeting. None of these rules, however, is able to implement the welfare-maximizing resource allocation for the whole range of parameter combinations. Which one comes closest to the optimal rule as measured by its welfare implications depends on the degree of the cross-country interdependence in production, measured by $\alpha$, and the relative importance of productivity and cost-push shocks.

When evaluating the welfare implications of alternative targeting rules one has to keep in mind that the criterion for global welfare, given in equation (16), only depends on second moments. Non-stochastic terms therefore need not be considered in the formulations of the money supply rules and when calculating welfare. Since fixed-price agents enter a period with preset prices, optimal prices given in equations (11) and (12) are non-stochastic and therefore play no role in the welfare analysis. To allow for a meaningful discussion of price targeting rules, the monetary rules and welfare in this section are derived for $v<1$.

The welfare levels under each targeting rule are given in Table (2).

Table 2: Targeting Rules and Welfare

\begin{tabular}{|c|c|}
\hline Target & Welfare \\
\hline Producer Price & $\begin{aligned} \tilde{W}^{G, P P I}= & -\left[\left(v(1-b)-\frac{1}{2} v\left(1+\eta(2 \alpha-1)^{2}\right)\right)^{2}+\left(v b-\frac{1}{2} v\left(1-\eta(2 \alpha-1)^{2}\right)\right)^{2}\right] \sigma_{K}^{2} \\
& -\left[\frac{1}{2} v^{2}\left(1+u^{2}\right)+(1-v)^{2}(1-b)+v(1-v)\left(1+\eta(2 \alpha-1)^{2}\right)\right] \sigma_{\varphi}^{2}\end{aligned}$ \\
\hline Consumer Price & $\tilde{W}^{G, C P I}=-\left[\frac{1}{2} v(2-v)+(1-v)^{2}(1-b)\right] \sigma_{\varphi}^{2}-\frac{1}{2} v^{2}(2 b-1)^{2} \sigma_{K}^{2}$ \\
\hline Money Supply & $\tilde{W}^{G, M S}=-2 v^{2}\left(b(b-1)+\frac{1}{2}\right) \sigma_{K}^{2}-(1-b)(1-v(2-v)) \sigma_{\varphi}^{2}$ \\
\hline
\end{tabular}




\subsection{Numerical Example}

The welfare results are further illustrated with the help of a numerical example. The parameter setting chosen for the numerical simulation is taken from the literature. The share of fixed price agents is assumed to be $v=0.75$ so that a certain degree of price flexibility is retained. For the parameter measuring the degree of pass-through in the home and foreign country we assume $\eta=\eta^{*}=0.46$, which corresponds to empirical evidence for the short run average pass-through elasticities across OECD countries (see, e.g., CAmpa and Goldberg, 2005 and Choudhri and Hakura, 2001).

We examine three different cases. In the first case, both productivity and costpush shocks are equally important. Formally, $\sigma_{\varphi}^{2}=\sigma_{K}^{2}=1$. In the second case, we suppose that productivity shocks are much more important than cost-push shocks. Formally, this case can be captured by assuming that $\sigma_{K}^{2}=1$ and $\sigma_{\varphi}^{2}=1 / 3$. In the third case, the assumption concerning the relative importance of shocks is reversed, i.e. we now suppose that $\sigma_{K}^{2}=1 / 3$ and $\sigma_{\varphi}^{2}=1$. Figures (1)-(3) summarize the welfare results for varying degrees of the home bias parameter $\alpha$.

Figure (1) clearly shows that a policy such as monetary targeting that allows for some price flexibility is welfare superior to strictly targeting a price index if both types of shocks are highly volatile. ${ }^{20}$ Demand for intermediate goods can be smoothed most effectively by stabilizing a combination of real aggregates and prices as in the case of monetary targeting. Thus, the needed flexibility in prices in the presence of substantial cost push shock volatility is allowed for.

A key point of this paper, as pointed out above, is that work effort in the home country generally depends on all types of shocks in a highly interdependent world irrespective of the country they hit. A policy of CPI targeting is therefore generally superior in welfare terms to targeting the producer price index. In line with the optimal monetary policy, monetary policy under CPI targeting responds to all shocks (see Table 1). Producer and consumer price index targeting only generate almost equal welfare results if $\alpha$ is around $1 / 2$. In this case, both strategies imply similar responses to productivity shocks at home and abroad (see Table 1). The different responses to foreign cost-push shocks under producer and consumer price index targeting then are only of the second order. Since an equal share of consumption spending is allocated to home and foreign goods, increases in final goods prices have an identical impact on work effort in the home and foreign country if there is no home bias in production. Hence, producer price index targeting which implies a quite strong monetary policy reaction to the domestic 
Figure 1. Welfare Performance of Simple Targeting Rules for $\sigma_{\varphi}^{2}=\sigma_{K}^{2}=1$

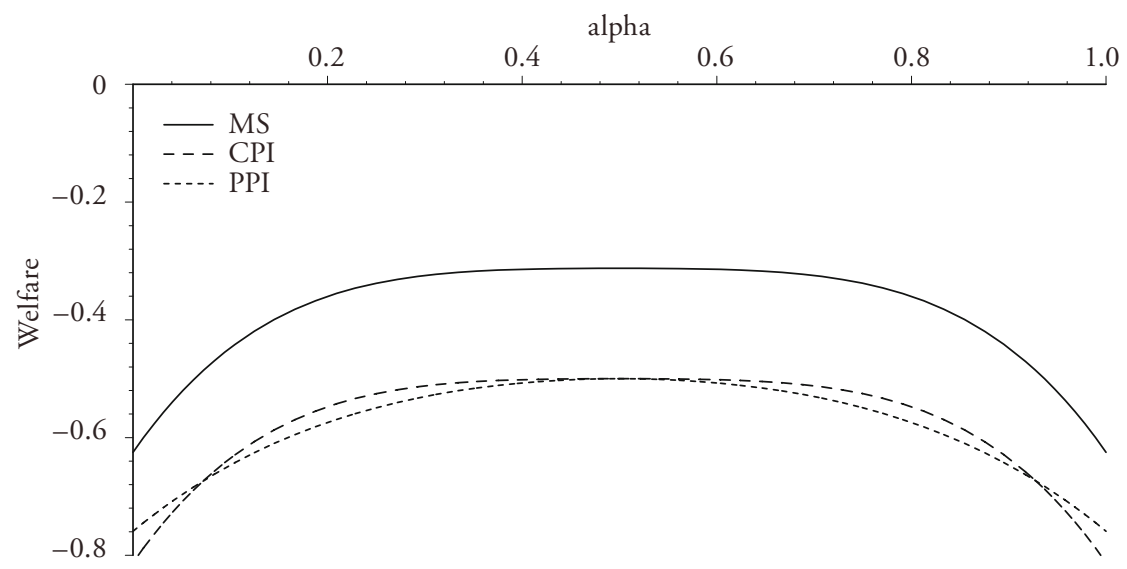

cost-push shock generates identical welfare results as CPI targeting that calls for a (weaker) monetary policy reaction to both $\varphi$ and $\varphi^{*}$.

In a large number of studies, however, producer price index targeting has been found to be a monetary policy strategy that is able to implement the welfare-maximizing resource allocation. ${ }^{21}$ These studies argue that targeting producer prices may bring about the welfare-maximizing resource allocation because the distortions created by price stickiness are neutralized. However, the results displayed in Figure (1) clearly indicate that stabilizing the prices of domestically produced consumption goods is not sufficient to stabilize work effort. If productivity and cost-push shocks are equally volatile, a policy of targeting the producer price index generally generates the largest welfare loss of all rules considered. In this model, the analysis of the optimal policy rule above clearly demonstrates that the welfare-maximizing resource allocation can only be implemented if the policymakers also respond to cost-push shocks abroad, i.e. to shocks that only affect foreign goods prices (as long as $\eta \neq 0, \eta \neq 1$ and $v<1$ as discussed above).

Only for a very special parameter combination, producer price index targeting is able to implement the welfare-maximizing (flex-price) resource allocation even if all producers are unable to readjust prices after the monetary policy decisions have been made $(v=1)$. This is the case if no cost-push shocks occur (their variance is assumed to be equal to zero) and exchange rate changes fully pass through

21 See the literature cited in the Introduction. 
Figure 2. Welfare Performance of Simple Targeting Rules $\sigma_{K}^{2}=1$ and $\sigma_{\varphi}^{2}=1 / 3$

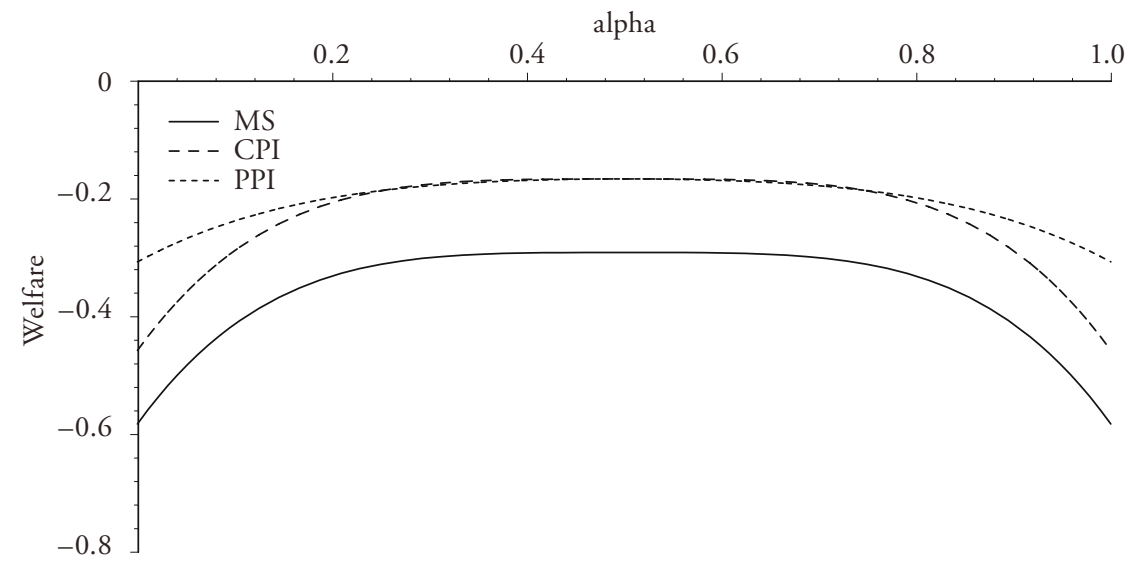

into prices. For this parameter combination, producer price index targeting perfectly stabilizes producers' mark-up irrespective of $\alpha$ and thus removes the incentive for price changes. ${ }^{22}$ Thus, the standard case as laid out by, e.g., Clarida, Gali and Gertler (2002) is replicated.

We now turn to the case where productivity shocks are the major source of concern.

Even if monetary policy is predominantly concerned with productivity shocks, producer price targeting as recommended by other studies (see, e.g., SutherLAND, 2005) does not generally constitute the best simple rule. We show that this result needs to be qualified if the increasing vertical integration of countries is explicitly taken into consideration. Then, the answer to the question which price targeting rule is best in welfare terms depends on how interdependent countries are, as measured by $\alpha$.

CPI targeting is less strict than producer price index targeting since it allows for some flexibility in producer prices. This is sufficient to render CPI targeting welfare-superior to producer price index targeting in the presence of weak costpush shocks for a wide range of values for $\alpha$. Producer price index targeting only generates the best welfare results if the home bias in production is relatively pronounced, i.e. the cross-country interdependence in production is either rather weak or rather strong. This is another central result of this paper. Intuitively, 
Figure 3. Welfare Performance of Simple Targeting Rules $\sigma_{K}^{2}=1 / 3$ and $\sigma_{\varphi}^{2}=1$

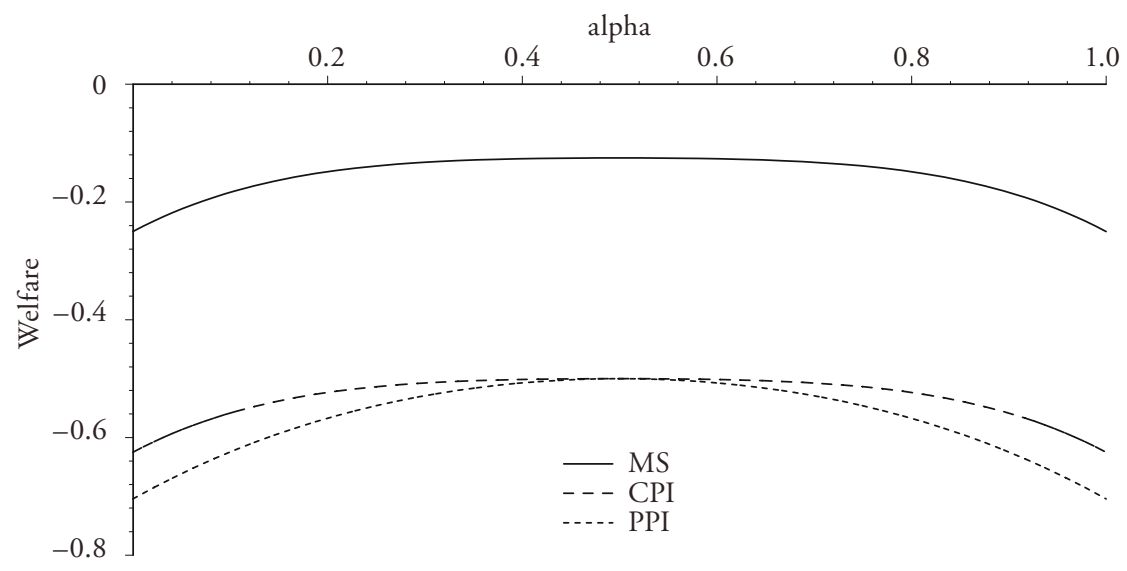

stabilizing foreign goods prices (as is done under consumer price index targeting), too, does not yield an additional benefit in terms of work effort stabilization in the home economy if $\alpha$ is relatively high. For similar reasons, focusing on the stabilization of domestically produced goods is better than the stabilization of domestically consumed goods if $\alpha$ is relatively low. From a global point of view, it does not matter whether monetary adjustments by the home or the foreign policymaker offset the impact of home or foreign shocks on work effort. If the cross-country interdependence in production is quite pronounced, home work effort is mainly stabilized by the foreign policymaker's monetary policy measures to stabilize foreign producer prices while the home policymaker's adjustments lead to a stabilization of work effort in the foreign country.

Monetary targeting which allows for some price flexibility in exchange for the stability of a real aggregate (consumption) is clearly inferior in welfare terms to both producer and consumer price index targeting if cost-push shocks are by far less important than productivity shocks. However, allowing prices to fluctuate to some extent is clearly the best targeting rule if cost-push shocks predominate (see Figure (3)). This is also stressed by Sutherland (2005). As discussed there, policies that allow for price movements like monetary targeting are superior to price targeting rules in the presence of cost-push shocks. Cost-push shocks directly destabilize consumption goods prices and thus affect work effort. Monetary policy strategies that allow for a combination of price level and real aggregates stabilization such as monetary targeting are therefore superior in welfare 
terms to rules that exclusively focus on stabilizing price indices such as producer or consumer price index targeting. Strictly targeting the producer price index is the least favorable targeting rule for this parameter combination. CPI targeting which, as pointed out above, leaves some room for variability in producer prices performs slightly better in welfare terms.

\section{Conclusions}

A vertical chain of production and trade along this chain have been found to be a characteristic feature of globalized markets. Starting from this stylized fact, this paper examines how a multistage production process that involves more than one country affects the choice of a monetary policy target. While prices of intermediate goods are assumed to be perfectly flexible, a fraction of consumption goods prices has to be set in advance. It is assumed that there is full passthrough of exchange rate changes into intermediate goods prices, but a less than perfect pass-through into the prices of final consumption goods.

We are concerned first with the optimal monetary policy if policies are coordinated, i.e. with the policy rules that maximize global welfare. In a second step we investigate which simple, i.e. non-optimal, targeting rule best supports the welfare maximizing policy. Our key results can be summarized as follows. Pursuing an inward-looking policy, as suggested in recent work, is clearly not optimal in this set-up. Generally, the welfare-maximizing monetary policy implies a response to both productivity and cost-push shocks irrespective of their origin. A comparison of the welfare effects of a range of simple targeting rules shows no unambiguous result. The degree of cross-country production interconnectedness and the relative importance of cost-push and productivity shocks are keys for the welfare ranking. While the relative importance of productivity and costpush shocks is decisive for the question whether the policymaker should follow a price targeting rule or not, the degree of vertical integration determines which simple price targeting rule performs best.

Producer price and consumer price targeting are welfare-inferior to a rule like monetary targeting that allows for some degree of price flexibility in the presence of comparatively strong cost-push shocks. If, however, productivity shocks are predominant, strictly targeting price indices such as the producer price index or the CPI is welfare superior to targeting other monetary policy objectives. In this case, producer price index targeting as recommended in large parts of the literature only generates better welfare results than CPI targeting if vertical integration between countries is either rather low or rather high. 
In future work, it would be interesting to relax some of the more restrictive assumptions to check the robustness of the results. Credibility problems and dynamic aspects are generally abstracted from. Furthermore, the inclusion of other sources of nominal inertia along the lines of ERCEG, HENDERson and LEVIN (2000) might prove fruitful in future research.

\section{Appendix}

\section{Simple Policy Rules}

\section{Producer Price Targeting}

A policy of producer (domestic) price index targeting can formally be formulated as $\hat{P}_{H}=0$ and $\hat{P}_{F}^{*}=0$ in our model. The producer price indices, i.e. the indices of domestically produced goods, are given by

$$
\begin{aligned}
\hat{P}_{H} & =v \hat{P}_{H, 1}+(1-v)\left[\hat{M}+\hat{\varphi}+\alpha \hat{K}+(1-\alpha) \hat{K}^{*}\right] \\
\hat{P}_{F}^{*} & =v \hat{P}_{F, 1}^{*}+(1-v)\left[\hat{M}^{*}+\hat{\varphi}^{*}+\alpha \hat{K}^{*}+(1-\alpha) \hat{K}\right] .
\end{aligned}
$$

As discussed in the main text, the welfare measure only depends on variances. The prices set by fixed price producers are by definition non-stochastic so that they are not relevant for welfare calculations. Bearing this in mind, (in order to simplify notation) the monetary rules under producer price targeting omit all non-stochastic terms and can be expressed as in Table (1).

\section{Consumer Price Targeting}

Targeting the consumer price index means that both policymaker adopt rules that ensure that $\hat{P}=0$ and $\hat{P}^{*}=0$ ex-post. The consumer price indices, i.e. the indices of domestically consumed goods, are given by

$$
\begin{aligned}
\hat{P} & =\frac{1}{2}\left\{v \hat{P}_{H, 1}+(1-v)\left[\hat{M}+\hat{\varphi}+\alpha \hat{K}+(1-\alpha) \hat{K}^{*}\right]\right\} \\
& +\frac{1}{2}\left\{\begin{array}{l}
v \hat{\stackrel{P}{F, 1}}_{F,}^{*}+(1-v)\left[\hat{M}^{*}+\hat{\varphi}^{*}+\alpha \hat{K}^{*}+(1-\alpha) \hat{K}\right] \\
+\eta \hat{S}+(1-v)(1-\eta) \hat{S}
\end{array}\right\}
\end{aligned}
$$




$$
\begin{aligned}
\hat{P}^{*}= & \frac{1}{2}\left\{v \hat{P}_{F, 1}^{*}+(1-v)\left[\hat{M}^{*}+\hat{\varphi}^{*}+\alpha \hat{K}^{*}+(1-\alpha) \hat{K}\right]\right\} \\
& +\frac{1}{2}\left\{\begin{array}{l}
v \hat{\widetilde{P}}_{H, 1}+(1-v)\left[\hat{M}+\hat{\varphi}+\alpha \hat{K}+(1-\alpha) \hat{K}^{*}\right] \\
-\eta \hat{S}-(1-v)(1-\eta) \hat{S}
\end{array}\right\} .
\end{aligned}
$$

Rearranging and omitting all non-stochastic terms yields the monetary policy rules given in Table (1).

\section{References}

Batini, Nicoletta, Richard Harrison and Stephen Millard (2003), "Monetary Policy Rules for an Open Economy", Journal of Economic Dynamics and Control, 27, pp. 2059-2094.

Bullard, James and Aarti Singh (2008), "Worldwide Macroeconomic Stability and Monetary Policy Rules", Journal of Monetary Economics, 55, pp. S34-S47.

Calvo, Guillermo (1983), "Staggered Prices in a Utility-Maximizing Framework", Journal of Monetary Economics, 12, pp. 383-398.

Campa, Jose and Linda Goldberg (2005), "Exchange Rate Pass-Through Into Import Prices", Review of Economics and Statistics, 87, pp. 679-690.

Campa, Jose, Linda Goldberg and Jose Gonzalez-Minguez (2005), "Exchange Rate Pass-Through to Import Prices in the Euro Area”, Staff Report No. 219, Federal Reserve Bank of New York, New York.

Choudhri, Ehsan and Dalia Hakura (2001), "Exchange Rate Pass-Through to Domestic Prices: Does the Inflationary Environment Matter?”, International Monetary Fund Working Paper 01/194, International Monetary Fund, Washington, DC.

Clarida, Richard, Jordi Gali and Mark Gertler (2002), "A Simple Framework for International Monetary Policy Analysis", Journal of Monetary Economics, 49, pp. 879-904.

Cole, Harold and Maurice Obstaeld (1991), "Commodity Trade and International Risk Sharing: How Much Do Financial Markets Matter?”, Journal of Monetary Economics, 28, pp.3-24.

Corsetti, Giancarlo and Paolo Pesenti (2005), "International Dimensions of Optimal Monetary Policy”, Journal of Monetary Economics, 52, pp. 281-305. 
Devereux, Michael and Charles Engel (2007), "Expenditure Switching vs. Real Exchange Rate Stabilization: Competing Objectives for Exchange Rate Policy", Journal of Monetary Economics, 54, pp. 2346-2374.

Devereux, Michael, Pilip Lane and Juanyi Xu (2006), "Exchange Rates and Monetary Policy in Emerging Market Economies", Economic Journal, 116, pp. 478-506.

Engel, Charles and John Rogers (2001), "Deviations from Purchasing Power Parity: Causes and Welfare Costs", Journal of International Economics, 55, pp. 29-57.

Erceg, Christopher, Dale Henderson and Andrew Levin (2000), "Optimal Monetary Policy with Staggered Wage and Price Contracts", Journal of Monetary Economics, 46, pp. 281-313.

Feve, Patrick, Julien Matheron and Celine Poilly (2007), "Monetary Policy Dynamics in the Euro Area", Economics Letters, 96, pp. 97-102.

Gali, Jordi and Tommaso Monacelli (2005), "Monetary Policy and Exchange Rate Volatility in a Small Open Economy", Review of Economic Studies, 72, pp. 707-734.

Hoermann, Markus and Andreas Schabert (2009), "An Interest Rate Peg Might Be Better Than You Think", fc. in Economics Letters.

Huang, Kevin and Zeng Liu (2004), "Production Interdependence and Welfare”, ECB Working Paper No. 355, European Central Bank, Frankfurt.

Hummels, David, Jun Ishi and Kei-Mu Yi (2001), "The Nature and Growth of Vertical Specialization in World Trade", Journal of International Economics, 54, pp. 75-96.

Kollmann, Robert (2002), "Monetary Policy Rules in the Open Economy: Effects on Welfare and Business Cycles", Journal of Monetary Economics, 49, pp. 989-1015.

Leith, Campbell and Simon Wren-Lewis (2009), "Taylor Rules in the Open Economy", fc. in European Economic Review.

McCallum, Benett and Edward Nelson (1999), "Nominal Income Targeting in an Open-Economy Optimizing Model", Journal of Monetary Economics, 43, pp. 553-578.

McCallum, Benett and Edward Nelson (2005), "Targeting versus Instrument Rules for Monetary Policy", Federal Reserve Bank of St. Louis Review, 87, pp. 597-611.

Obstreld, Maurice (2001), "International Macroeconomics: Beyond the Mundell-Fleming Model”, International Monetary Fund Staff Papers, 47, pp. 1-39.

Obstreld, Maurice and Kenneth Rogoff (1995), "Exchange Rate Dynamics Redux", Journal of Political Economy, 103, pp. 624-660. 
Obstfeld, Maurice and Kenneth Rogoff (2002), "Global Implications of Self-Oriented National Monetary Rules", Quarterly Journal of Economics, 117, pp. 503-536.

Parsley, David and Shang-Jin Wei (2001), "Explaining the Border Effect: The Role of Exchange Rate Variability, Shipping Costs, and Geography”, Journal of International Economics, 55, pp. 87-105.

Shi, Kang and Juanyi Xu, (2007), "Optimal Monetary Policy with Vertical Production and Trade", Review of International Economics, 15, pp. 514-537.

Smets, Frank and Raf Wouters (2002), "Openness, Imperfect Exchange Rate Pass-Through and Monetary Policy", Journal of Monetary Economics, 49, pp. 947-981.

Sutherland, Alan (2004), "International Monetary Policy Coordination and Financial Market Integration”, CEPR Discussion Paper No. 4251, London.

Sutherland, Alan (2005), "Cost-Push Shocks and Monetary Policy in Open Economies”, Oxford Economic Papers, 57, pp. 1-33.

Sutherland, Alan (2006), "The Expenditure Switching Effect, Welfare and Monetary Policy in a Small Open Economy", Journal of Economic Dynamics and Control, 30, pp. 1159-1182.

Svensson, Lars (2002), "Inflation Targeting: Should It Be Modeled as an Instrument Rule or a Targeting Rule?”, European Economic Review, 46, pp. 771-780.

Svensson, Lars (2005), "Targeting Rules vs. Instrument Rules for Monetary Policy: What Is Wrong with McCallum and Nelson?", Federal Reserve Bank of St. Louis Review, 87, pp. 613-626.

TaYlor, John(1993), "Discretion Versus Policy Rules in Practice", CarnegieRochester Conference Series on Public Policy, 39, pp. 195-214.

YI, Kei-Mu (2003), "Can Vertical Specialization Explain the Growth of World Trade?", Journal of Political Economy, 111, pp. 52-102.

\section{SUMMARY}

This paper studies monetary policy in an optimizing two-country model. We suppose a two-step production process that is associated with vertical trade. Prices of final consumption goods are sticky and pass-through can be incomplete. Monetary authorities should respond to both home and foreign shocks in this set-up. Which simple, i.e. non-optimal, targeting rule best supports the welfare maximizing policy hinges critically on the degree of the cross-country interdependence in production and the relative importance of productivity and cost-push 
shocks. We argue that the relative volatility of productivity and cost-push shocks determines whether the monetary authority should follow a price targeting rule whereas the degree of vertical integration determines which simple price targeting rule (producer or consumer price index targeting) is best. 